\title{
Whole body vibrations: experimental assessment of anthropometric differences on the effects of WBV exposure in quarry workers
}

\author{
G. Alfaro Degan, D. Lippiello \& M. Pinzari \\ Department of Engineering, ROMA TRE University, Italy
}

\begin{abstract}
The human biomechanical response to whole body vibrations (WBV) is affected by the inertial characteristics of the body itself, among which the anthropometric parameters of the subject, such as body mass and shape, are the most relevant.

Although human exposure to mechanical vibration is universally recognized as a significant risk factor for workers, Directive 2002/44/EC indicates the minimum health and safety requirements regarding the exposure to risks arising from physical agents, stating that risk assessment may be essentially based on appropriate information available from the manufacturer without the obligation of carrying out any measurements. For this reason, information such as the machine type and model, operating conditions, driving style, soil type, and workplace characteristics are declared together with the manufacturer's vibration measurements carried out in accordance with specific ISO EN Standards. Clearly, these data do not refer to the specific operating conditions and they do not consider the inertial and geometric parameters of the driver himself (as if these factors could not affect the exposure results). This study aims to evaluate the relationship between the WBV exposure values of loader vehicle drivers and their main anthropometric characteristics, i.e., height and weight. In this case study, the responses of drivers to vibrations from the same vehicle are analysed by means of several sampling campaigns. A correlation study is then presented along with some considerations which are proposed in order to quantify the observed differences and to predict exposure values from anthropometric data. Keywords: whole body vibration, anthropometric differences, loader vehicle workers.
\end{abstract}




\section{Introduction and motivation}

Extractive activities and quarries in general constitute an atypical sector as they give rise to numerous critical issues in relation to occupational exposure of workers in this field. Extractive plant operation inevitably produces physical agents such as noise and vibrations, as well as the emission of numerous airborne pollutants, all of which may have a considerable detrimental effect on the health of the machinery operators.

This study is conducted in the field of health and safety in the workplace concerning the evaluation of the risk of exposure to physical agents with particular regard towards whole body vibrations (WBV). The paper aims to evaluate any correlation which may exist between machinery vibrations and the body characteristics of the machinery operators who are exposed to them.

It is well known that, ever since the first studies carried out on machinery, [1], human exposure to mechanical vibrations may be a substantial risk factor for the machinery operators and may have a detrimental effect on their health, [2]. The EU legislated on question with the enactment of Directive 2002/44/CE, introducing related technical standards [3-5]. It has become obligatory for the company in charge of the activity to evaluate such risks, to determine the daily dose to which the machinery operators are exposed, and to implement the prescribed minimum health and safety measures by various means [6] in order to reduce their effects.

Among the first consequences of this legislation is the focus of attention on the levels of exposure linked to the use of means of transport in general and in particular heavy machinery vehicles with regard to the planning stages and determining containment measures [7], as well as the phase in which the exposure itself is evaluated [8].

Due to its particular characteristics, the extractive sector has often been chosen as the ideal scenario in which to analyse the problem [9], both in terms of purely monitoring $[10,11]$, as well as of studying the correlated effects on operators health [12-14] and synergistic effects [15]. More specifically, the typical quarry machinery and vehicles [16], are a source of particularly significant vibrations, especially when the vehicles are used to carry out the heavy loading and unloading activities for which they were designed [17].

The scientific community has predominantly concentrated on the differences in terms of exposure linked to the type of machinery [18] or to the degree of its wear and tear [19] as well as other variables such as the type of terrain involved, the driving speed, or the ergonomics of the operator's seat [20].

From the beginning, in the interests of monitoring, it was deemed necessary be able to reliably predict the degree of exposure to the physical agent in question through further study focused on defining prediction methods and models [21-24].

Since the surrounding experimental conditions (such as the type of source machinery, the working environment, the time period of exposure, and the driving style) were apparently identical in these cases, it seemed natural to investigate possible causes of such differences. Therefore, this paper aims 
to analyse the variability of WBV in relation to the physical characteristics of the subjects (considering subjects' height and weight as parameters) in order to determine the nature of any such variability in this respect and then to carry out a quantitative analysis should such a correlation exist.

\section{Materials and methods}

\subsection{Methods of risk evaluation of occupational exposure to WBV}

According to European Directive 2002/44/EC [11], the assessment of WBV (Whole Body Vibration) exposure for a seated person requires the calculation of the daily exposure parameter $\mathrm{A}(8)$, expressed as the equivalent continuous root mean squared (RMS) acceleration over an eight-hour period:

$$
A(8)=a_{w} \sqrt{\frac{T_{e s p}}{8}} m / s^{2}
$$

In equation (1), $\mathrm{a}_{\mathrm{w}}$ is the equivalent continuous frequency-weighted RMS acceleration over a $T_{\text {esp }}$ period (where $T_{\text {esp }}$ is the duration of the occupational exposure).

The calculation of the equivalent acceleration $a_{w}$ involves determining the three frequency-weighted components $\mathrm{a}_{\mathrm{wx}}, \mathrm{a}_{\mathrm{wy}}$ and $\mathrm{a}_{\mathrm{wz}}$ along the three orthogonal axes of a standard reference system established by the International Standard ISO 2631-1 (97). The horizontal axes of vibration, $x$ and $y$, define the seat plane, where the $\mathrm{x}$ axis is the fore-and-aft vibration; the $\mathrm{y}$ axis is the lateral vibration; and the $\mathrm{z}$ axis is the vertical vibration. Specific weighting factors are indicated by ISO 2631 to account for different sensitivities of the human body depending on the vibration frequency. For a seated person the frequency-weighted acceleration components along $\mathrm{x}$ and $\mathrm{y}$ must be multiplied by a factor of 1.4, accounting for the higher sensitivity of the human body along these directions when considering the frequency range of maximum sensitivity (between 0.5 and $2 \mathrm{~Hz}$ for the $\mathrm{x}$ and $y$ axes, and between 4 and $8 \mathrm{~Hz}$ for the $\mathrm{z}$ axis). According to Equation (2), only the highest of the three acceleration values registered along the three axes is included in the calculation of the exposure parameter $\mathrm{A}(8)$ :

$$
\mathrm{a}_{\mathrm{w}}=\max \left(\mathrm{K}_{\mathrm{x}} * \mathrm{a}_{\mathrm{wx}}, \mathrm{K}_{\mathrm{y}}{ }^{*} \mathrm{a}_{\mathrm{wy}}, \mathrm{K}_{\mathrm{z}} * \mathrm{a}_{\mathrm{wz}}\right)
$$

where:

$$
\mathrm{K}_{\mathrm{x}}=\mathrm{K}_{\mathrm{y}}=1.4 ; \mathrm{K}_{\mathrm{z}}=1
$$

The parameter $\mathrm{A}(8)$ is compared with a daily exposure action value $\left(E A V=0.5 \mathrm{~m} / \mathrm{s}^{2}\right)$ and a daily exposure limit value $\left(E L V=1.15 \mathrm{~m} / \mathrm{s}^{2}\right)$.

The value of $\mathrm{A}(8)$ can be a function of any of the three axial vibration components, depending on the type of vehicle, the task performed, and the specific field conditions. The maximum acceleration component for a given vehicle, is often the result of a combination of various different work phases (e.g., driving along the flat, or going uphill, or loading etc.), each characterized 
by a different dominant axis. In such cases Equation (3) is used to calculate the exposure parameter

$$
A(8)=\sqrt{\frac{1}{8} \sum_{i=1}^{n} a_{w i}^{2} \cdot T_{i}}
$$

where $\mathrm{a}_{\mathrm{wi}}$ and $\mathrm{T}_{\mathrm{i}}$ represent the highest component of the equivalent RMS (root mean square) acceleration and the exposure duration for the i-th work phase respectively.

When $\mathrm{A}(8)$ is higher than the action value EAV, a risk containment programme must be determined to reduce the level of exposure, which may not exceed the limit value ELV.

As risk evaluation through the calculation of $\mathrm{A}(8)$ is outside the scope of this paper, we shall limit ourselves to studying the value of $\mathrm{a}_{\mathrm{w}}$, determined using the methods defined above (ISO 2631-1 (97)).

\subsection{Test environment and instrumentation}

The measurements were taken in relation to two distinct types of vehicle (see Figure 1):

- An articulated backhoe loader (FAI 575, Year 1991), weight 6.7 tonnes;

- A skid-steer loader model FAI 348, registered in 1997, weight 2.3 tonnes.

The acquisition of the data and its subsequent elaboration was carried out using a 4 channel Soundbook system. Having four channels allowed four different accelerometers to be measured simultaneously: the first was attached to the pillar of the vehicle in order to measure the phenomenon of the source vibration; the remaining three channels (the triaxial accelerometer) measured the vibrations transmitted to the driver's body through the $\mathrm{x}, \mathrm{y}$, and $\mathrm{z}$ axes (the transducer was positioned between the driving seat and the driver's buttocks).

The technical specifications and the positioning of the accelerometers are shown in table 1.

Due to the considerable weight of the machinery, the weight of the driver was considered irrelevant in the measurement of the vibrations of the machinery itself, thus it is assumed that there are no input errors owing to any variation in the physical configuration of the machinery-sample-instrument system of measurement.

\subsection{Experimental campaign}

During the experiment the subjects (the vehicle drivers) were asked to drive along a pre-established track at a constant speed for a total time of 120 minutes.

Each driver repeated the course 5 times for each of the two available vehicles, thus allowing an arithmetic mean to be calculated from 5 samples for each of the three axis measurements. 
Table 1: $\quad$ Instruments utilized.

\begin{tabular}{|c|c|c|}
\hline Model & Sensitivity & Position \\
\hline $\begin{array}{c}\text { Triaxial } \\
\text { accelerometer } \\
\text { SEN027-PCB } \\
356 \mathrm{~B} 40\end{array}$ & $\begin{array}{l}\mathrm{X} \text { axis: } 10.52 \mathrm{mV} /\left(\mathrm{m} / \mathrm{s}^{2}\right) \\
\mathrm{Y} \text { axis: } 10.55 \mathrm{mV} /\left(\mathrm{m} / \mathrm{s}^{2}\right) \\
\mathrm{Z} \text { axis: } 10.88 \mathrm{mV} /\left(\mathrm{m} / \mathrm{s}^{2}\right)\end{array}$ & $\begin{array}{l}\text { Driving seat of the vehicle } \\
\text { corresponding to the position } \\
\text { of the driver's sacroiliac } \\
\text { joints (his/her buttocks). }\end{array}$ \\
\hline $\begin{array}{c}\text { Uniaxial } \\
\text { accelerometer } \\
\text { PCB 393A03 }\end{array}$ & $\begin{array}{c}\text { Single axis: } 102.2 \\
\mathrm{mV} /\left(\mathrm{m} / \mathrm{s}^{2}\right)\end{array}$ & $\begin{array}{l}\text { Axis sensitive in the same } \\
\text { direction as the } Z \text { axis of the } \\
\text { triaxial accelerometer } \\
\text { (vertical axis). }\end{array}$ \\
\hline
\end{tabular}

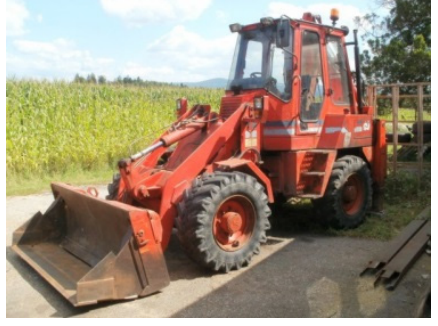

(a)

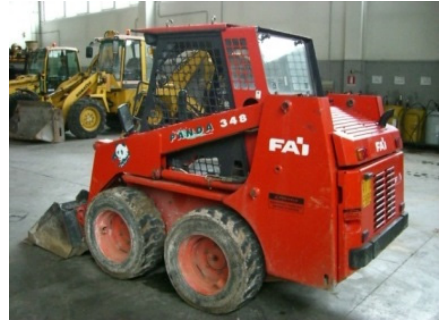

(b)

Figure 1: $\quad$ The machinery used: (a) a FAI 575 backhoe loader, (b) a FAI 348 skid-steer loader.

\subsubsection{Sample tested}

The population which underwent the test was comprised of two different groups of subjects, who were subdivided as follows.

- Group 1: 30 drivers (10 women and $20 \mathrm{men}$ ) of equal height of $174 \mathrm{~cm}$ (tolerance $\pm 1.5 \mathrm{~cm}$ ) and of variable weight.

- Group 2: 25 drivers (4 women and $21 \mathrm{men}$ ) of equal weight of $76 \mathrm{~kg}$ (tolerance $\pm 2 \mathrm{~kg}$ ) and of variable height.

At the end of the tests, each individual was attributed an arithmetic mean of the weighted acceleration values, relative to each of the three axes $\mathrm{x}, \mathrm{y}$ and $\mathrm{z}$, as indicated by (5):

$$
\bar{a}_{w x}=\frac{1}{5} \sum_{i=1}^{5} a_{w x_{i}} ; \bar{a}_{w y}=\frac{1}{5} \sum_{i=1}^{5} a_{w y_{i}} ; \bar{a}_{w z}=\frac{1}{5} \sum_{i=1}^{5} a_{w z_{i}}
$$

In accordance with Directive 2002/44/CE, the value assigned to $\mathrm{a}_{\mathrm{w}}$ is the highest of the three acceleration values of $\mathrm{K}_{\mathrm{x}}{ }^{*} \mathrm{a}_{\mathrm{wx}}, \mathrm{K}_{\mathrm{y}}{ }^{*} \mathrm{a}_{\mathrm{wy}}, \mathrm{K}_{\mathrm{z}}{ }^{*} \mathrm{a}_{\mathrm{wz}}$ (see (2)) expressed in $\mathrm{m} / \mathrm{s}^{2}$ :

$$
a_{w}=\max \left(K_{x} * \bar{a}_{w x} ; K_{y} * \bar{a}_{w y} ; K_{z} * \bar{a}_{w z}\right)
$$




\section{Results}

\subsection{Characteristics of the source signal and relative repeatability}

As mentioned above $(\S 2.2)$, in order to check the repeatability of the source vibration signal, the vibrations of the two test vehicles themselves (FAI 348, FAI 575) were measured using an accelerometer (uniaxial accelerometer PCB 393A03) which was attached to a/the pillar/column of the bodywork/chassis. It was deemed of the utmost importance that the source signal be kept as constant as possible so that any differences in results obtained from the measurements between subject's WBV (whole body vibrations) might be considered to be due solely to differences in the body characteristics between subjects.

From analysing the acceleration values of the vibrations, within the frequency range of $0.04-500 \mathrm{~Hz}$, recorded on the pillars/columns of the two test vehicles, means and standard deviations were obtained (as shown in table 2).

Table 2: $\quad$ Source signal characteristics.

\begin{tabular}{|c|c|c|}
\hline Vehicle & Arithmetic mean $\left(\mathrm{m} / \mathrm{s}^{2}\right)$ & Standard deviation $\left(\mathrm{m} / \mathrm{s}^{2}\right)$ \\
\hline FAI 348 & 0.23 & 0.008 \\
\hline FAI 575 & 0.28 & 0.007 \\
\hline
\end{tabular}

The low standard deviation indicates that the input was a substantially uniform vibration signal and thus exhibiting a good level of repeatability at the source.

\subsection{Presentation of the results}

The graphs showing the values of $\mathrm{a}_{\mathrm{w}}$ for the FAI 575 and the FAI 348 respectively, are given below, and are subdivided into the types of population tested (Group 1, fixed height, and Group 2, fixed weight).

\subsubsection{Backhoe loader Model FAI 575}

Figure 2 shows the results of the measurements recorded from Group 1 (fixed height of $174 \mathrm{~cm} \pm 1.5 \mathrm{~cm})$ expressed in terms of $a_{W \max }\left(\mathrm{m} / \mathrm{s}^{2}\right)$.

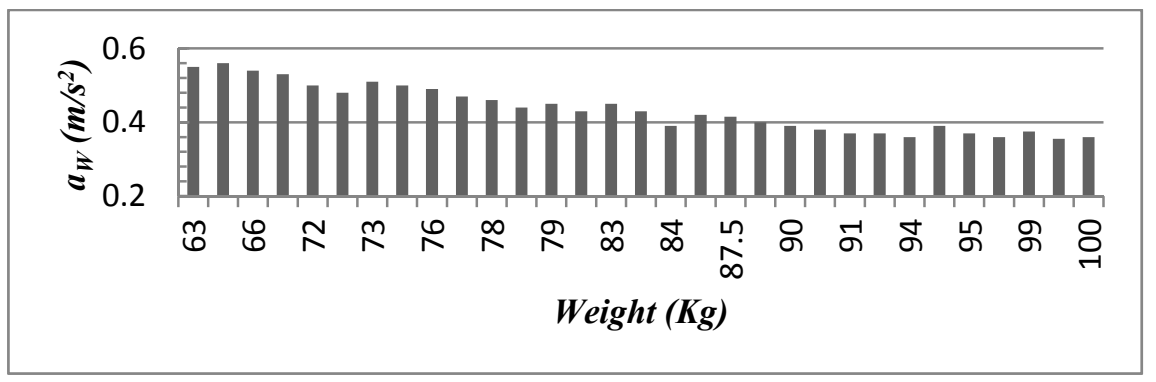

Figure 2: Results of the measurements recorded from Group 1 expressed in terms of $\mathrm{a}_{\mathrm{Wmax}}\left(\mathrm{m} / \mathrm{s}^{2}\right)$. 
Figure 3 shows the results of the measurements recorded from Group 2 (fixed weight of $76 \mathrm{Kg} \pm 2 \mathrm{~kg}$ ).

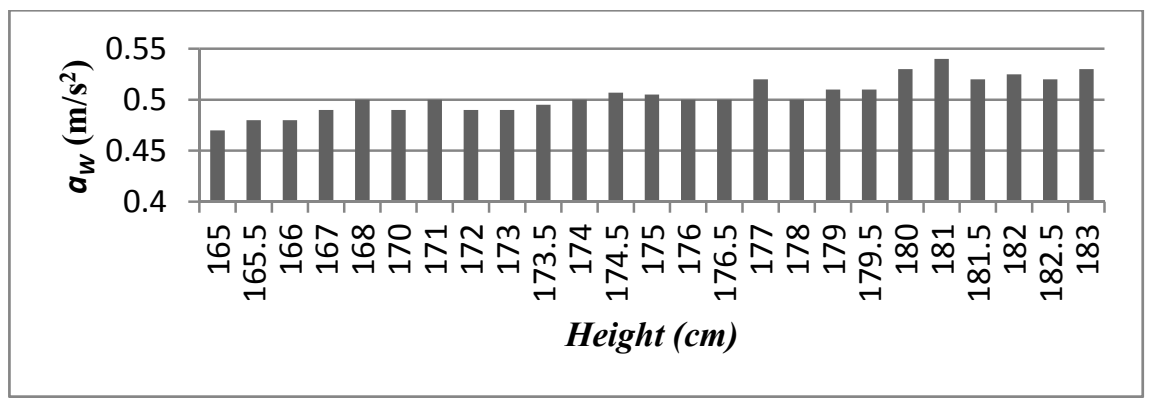

Figure 3: Results of the measurements recorded from Group 2.

\subsubsection{Skid-steer loader: model FAI 348}

Figure 4 shows the results of the measurements recorded from Group 1 (fixed height of $174 \mathrm{~cm}$ ), indicating in particular the trend of $a_{w}$ as a function of the different weights of the drivers who took part in the test.

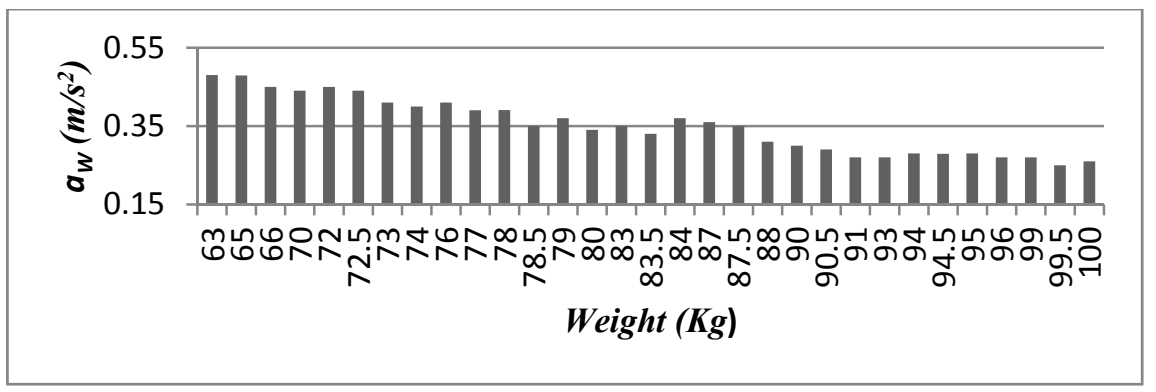

Figure 4: Results of the measurements recorded from Group 1.

\section{Discussion}

Using cubic polynomial functions, the trend lines are then calculated in order to highlight any trend connected with the values obtained from the measurements. The graphs in figures 5 and 6 show the cubic polynomial functions that best fit the measured data (the trend lines) for the model FAI 575 backhoe loader for Group 1 (fixed height of $174 \mathrm{~cm}$, variable weight), and for the model FAI 348 skid-steer loader again for Group 1.

Both the graphs clearly show the respective trend lines falling, highlighting the phenomenon of the WBV decreasing as body weight increases.

In contrast, the graphs shown below in figures 7 and 8 indicate analogous trend lines (cubic polynomials) this time for Group 2 (fixed weight of $74 \mathrm{~kg}$, variable height), for model Fai 575 (figure 7) and for model FAI 348 (figure 8) 
respectively. Lastly, figure 9 shows a comparison between the data from the two groups with variable weight and fixed height. The global trends of the two sets of measurements (cubic polynomials) appear to be similar.

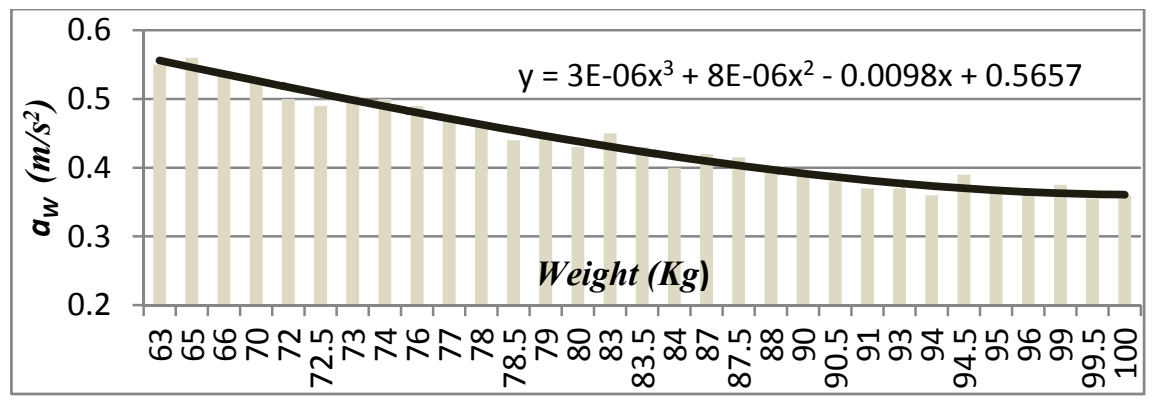

Figure 5: Trend line of the model FAI 575 backhoe loader.

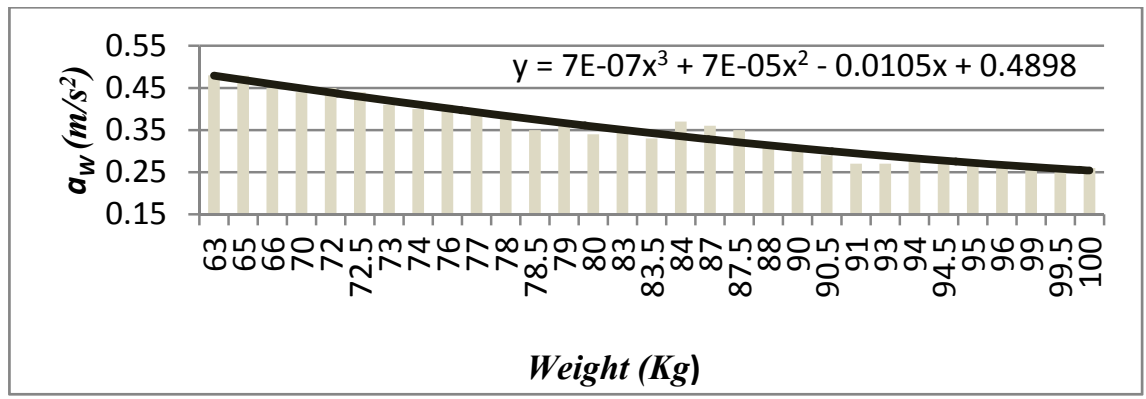

Figure 6: Trend line of the model FAI 348 skid-steer loader.

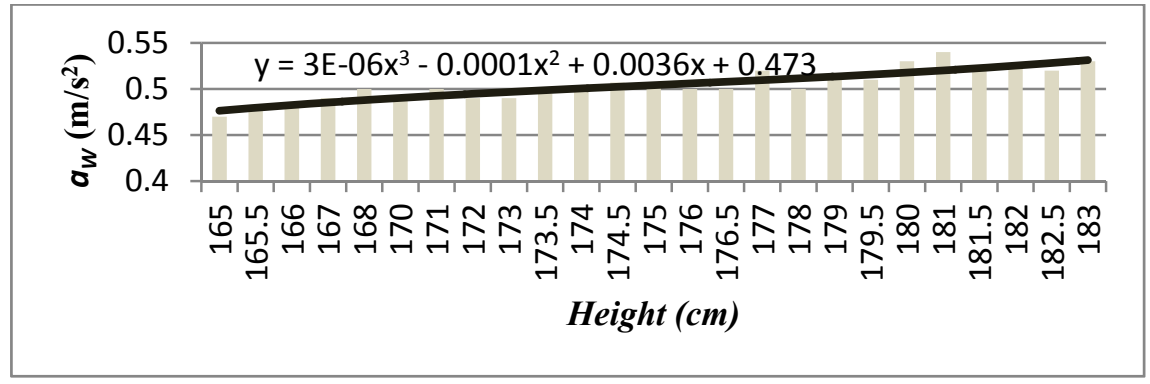

Figure 7: Trend line of the model FAI 575 backhoe loader. 


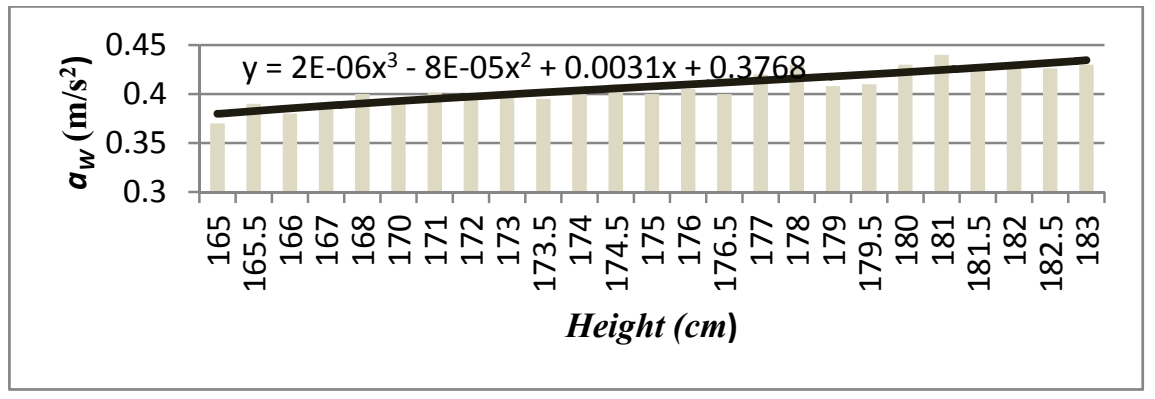

Figure 8: Trend line of the model FAI 348 skid-steer loader.

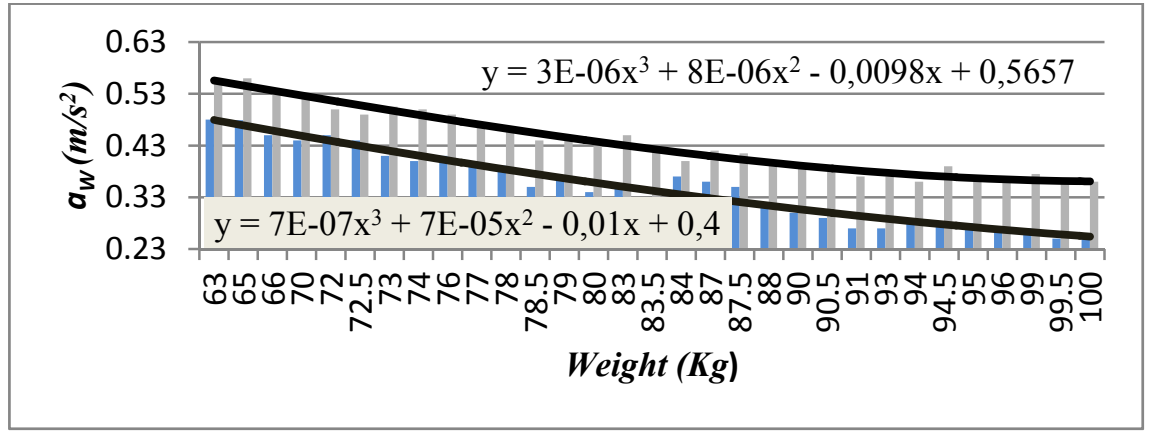

Figure 9: The trend lines from the WBV data measured with cubic polynomials.

\section{Conclusion}

The evaluation of whole body vibrations (WBV) is a particularly difficult problem, in that the phenomenon is generally affected by a vast number of variables. Results of measurements appear to be affected by subjective parameters such as the technique of the driver and the obsolescence of the vehicle as well as by environmental parameters such as the type of path taken by the vehicle and the speed it is driven.

One of the parameters which most evidently influences the extent of WBV appears to be connected with the subject's physical characteristics. Both the available literature and the experiments performed clearly confirm that for a given input vibration, the transmitted vibration depends strongly on the physical constitution of the subject exposed to the vibrations.

In order to investigate any dependence of parameters of body height and weight on the outcome of the WBV measured, it was first necessary to adopt an experimental methodology which provided an input vibration signal which was both as constant and as easily repeatable as possible. In order to do so, a standard course was established which all of the drivers in the experiment had to cover at 
a fixed speed in an identical time period. This arrangement was proven to be successful by the repeatability of the measured signal, indicated by its low standard deviation.

Secondly, thanks to the kind cooperation of students in the Engineering Department of Roma Tre University, two homogeneous groups of drivers were selected: one consisting of a population of identical height (Group 1) and the other of identical weight (Group 2).

The results of the WBV measurements carried out on the two groups of drivers (Group 1: 30 drivers, fixed height and variable weight; Group 2: 25 drivers, fixed weight and variable height) indicated a clear correlation between the value of $\mathrm{a}_{\mathrm{w}}$ and body characteristics.

In particular, for a given driver height, as driver weight increases, the value of $a_{w}$ decreases; and for a given weight, as height increases, the value of $a_{w}$ also increases.

In order to obtain data which are as reliable as possible, the experiments were repeated on two different vehicles (a model FAI 575 backhoe loader and a model FAI 348 skid-steer loader): in both experimental campaigns the output data gave $a_{w}$ values whose global trends appear to be very similar for both of the test vehicles.

The experiments brought the following results to the fore:

- The WBV are influenced by the body characteristics of the driver;

- When height is constant, subjects who are lighter in weight appear to be more exposed to WBV;

- When weight is constant, subjects who are taller appear to be more exposed to WBV.

Furthermore, plotting the resulting trend lines from the WBV data measured with cubic polynomials brought to light the fact that they are very similar (see fig. 9).

From this observation, one might assume that there is a mathematical function which, for a given value of WBV transmitted to a subject of a given weight, one would be able to predict the value of vibration for another driver of the same weight but of any given height.

Or alternatively following the same logical process, on the basis of the data obtained one could equally well predict the value of WBV of a driver of the same height as a subject which had been measured, but of a different weight.

\section{Acknowledgement}

The authors would like to give their thanks to the students from the academic year 2013-2014 of the Department of Engineering of Roma Tre University for their kind cooperation. 


\section{References}

[1] Village, J, Morrison, J.B., Leong, D.K.N. Whole Body vibration in underground load haul dump vehicles. Ergonomics, 32 (10), pp. 1167$1183,1989$.

[2] Lings, S, Leboeuf-Yde, C. Whole-body vibration and low back pain: a systematic, critical review of the epidemiological literature 1992-1999. International Archives of occupational and environmental health. 73 (5), pp. 290-287, 2000.

[3] Mechanical Vibration and Shock-Evaluation of Human Exposure to Whole-Body Vibration-Part 1: General Requirements. ISO Standard 2631$1,1997$.

[4] A1, Mechanical Vibration - Measurement and Calculation of Occupational Exposure to Whole-body Vibration with Reference to Health - Practical Guidance - EN 14253:2003.

[5] Earth-Moving Machinery - Laboratory Evaluation of Operator Seat Vibration. ISO Standard 7096, 2000.

[6] Alfaro Degan G, Lippiello D, Pinzari M. (2009). Occupational health and safety management systems: comparison between BS OHSAS 18001: 2007 and Italian Decree 81/2008. WIT Transactions on Biomedicine and Health, Vol. 14, WIT Press, 2009, ISSN: 1743-3525, pp. 401-409, doi: 10.2495/EHR090391.

[7] Donati, P. Survey of technical preventative measures to reduce wholebody vibration effects when designing mobile machinery. Journal of sound and vibration, 253 (1), pp. 169-183, 2003.

[8] Paddan, G.S., Griffin, M. J. Evaluation of whole-body vibration in vehicles. Journal of Sound and Vibration, 253 (1), pp. 195-213, 2002.

[9] Scarlett, A.J., Stayner, R., M. Whole-body Vibration on Construction, Mining and Quarrying Machines - Evaluation of Emission and Estimated Exposure Levels. HSE Books, Sudbury (Suffolk), 2005.

[10] Aye, S. A., Heyns, P. S. The evaluation of whole-body vibration in a South African opencast mine. Journal of the South African Institute of Mining and Metallurgy, 111 (11), pp. 751-757, 2011.

[11] Bernardo, C., Matos, M. L., Santos Baptista, J. Whole Body Vibration in open pit mining-a short review. In Occupational safety and Hygiene II, Proceedings of 10th Annual Congress of the Portuguese-Society-ofOccupational-Safety-and-Hygiene on Occupational Safety and Hygiene (SPOSHO). Ed: Arezes, P.M. et al. CRC Press-Taylor \& Francis Group, Vol. 2 pp. 459-464, 2014.

[12] Howard, B., Sesek, R., Bloswick, D. Typical whole body vibration exposure magnitudes encountered in the open pit mining industry. Work, 34 (3), pp. 297-303, 2009.

[13] Mandal, B. B., Srivastava, A. K. Musculoskeletal disorders in dumper operators exposed to whole body vibration at Indian mines. International Journal of Mining Reclamation and Environment, 24 (3), pp. 233-242, 2010. 
[14] Eger, T., Salmoni, A., Cann, A. et al. Whole-body vibration exposure experienced by mining equipment operators. Occupational Ergonomics, 6 (3-4), pp. 121-127, 2006.

[15] Alfaro Degan G, Lippiello D, Lorenzetti S, Multari F, Pinzari M. Combined evaluation of the noise and vibration at a travertino quarry. Recent Developments in Acoustics, Noise and Vibration. Proc. of $16^{\text {th }}$ International Congress on Sound and Vibration (ICSV16). Eds. M. Pawelczyk \& D. Bismorvol, IIAV: Krakow, vol. 3, pp. 1940-1947, 2009.

[16] Kumar, S. Vibration in operating heavy haul trucks in overburden mining. Applied Ergonomics, 35 (6), pp. 509-520, 2004.

[17] Frimpong, S., Galecki, G., Chang, Z. Dump truck operator vibration control in high-impact shovel loading operations. International Journal of Mining Reclamation and Environment, 25 (3), pp. 213-225, 2011.

[18] Massacci, G., Dentoni, V. Occupational exposure to whole-body vibration: unfavourable effects due to the use of old earth-moving machinery in mine reclamation. International Journal of Mining Reclamation and Environment, 27 (2), pp. 127-142, 2013.

[19] Mayton, A., Jobes, C., Miller, R. Comparison of whole body vibration exposures on older and newer haulage trucks at an aggregate stone quarry operations. In. ASME V, Proceeding of the International Design Engineering Technical Conference and Computer and Information in Engineering, Ed. ASME Group, Amer. Soc. Mechanical Engineers, pp. 685-691, 2008.

[20] Eger, T., Contratto, M., Dickey, J. Influence of Driving Speed, Terrain, Seat Performance and Ride Control on Predicted Health Risk Based on ISO 2631-1 and EU Directive 2002/44/EC. Journal of low frequency noise and vibration active control, 30 (4), pp. 291-312, 2012.

[21] Eger, T., Stevenson, J., Boileau, P. Predictions of health risks associated with the operation of load-haul-dump mining vehicles: Part 1-Analysis of whole-body vibration exposure using ISO 2631-1 and ISO-2631-5 standards. International Journal of Industrial Ergonomics, 38 (9-10), pp. 726-738, 2008.

[22] Eger, T., Stevenson, J., Boileau, P. Predictions of health risks associated with the operation of load-haul-dump mining vehicles: Part 2-Evaluation of operator driving postures and associated postural loading. International Journal of Industrial Ergonomics, 38 (9-10), pp. 801-8185, 2008.

[23] Alfaro Degan G, Lippiello D, Lorenzetti S, Pinzari M. (2013). Vibration assessing models: comparison between methods. WIT Transactions on Biomedicine and Health, Vol. 16, WIT Press, 2013, ISSN: 1743-3525, pp. 59-69, doi: 10.2495/EHR130061.

[24] Alfaro Degan G., Lippiello D., Pinzari M. A geostatistical approach to the functional analysis space technique: a case of study. Advances in Safety and Reliability - Proceedings of 16th European Safety and Reliability Conference (ESREL). Ed: Kolowrocki K, Taylor \& Francis, Vol. 1, pp. 45-52, 2005. 